\title{
Shared abstract representation of linguistic structure in bilingual sentence comprehension
}

\author{
Evan Kidd • Emilie Tennant • Sanjo Nitschke
}

Published online: 22 November 2014

(C) Psychonomic Society, Inc. 2014

\begin{abstract}
Although there is strong evidence for shared abstract grammatical structure in bilingual speakers from studies of sentence production, comparable evidence from studies of comprehension is lacking. Twenty-seven $(\mathrm{N}=27)$ EnglishGerman bilingual adults participated in a structural priming study where unambiguous English subject and object relative clause (RC) structures were used to prime corresponding subject and object RC interpretations of structurally ambiguous German RCs. The results showed that English object RCs primed significantly greater object RC interpretations in German in comparison to baseline and subject RC prime conditions, but that English subject RC primes did not change the participants' baseline preferences. This is the first study to report abstract crosslinguistic priming in comprehension. The results specifically suggest that word order overlap supports the integration of syntactic structures from different languages in bilingual speakers, and that these shared representations are used in comprehension as well as production.
\end{abstract}

Keywords Language comprehension · Structural priming · Relative clauses · Bilingualism

The degree to which the linguistic systems of bilingual speakers overlap is an enduring issue in psycholinguistic

E. Kidd $\cdot$ E. Tennant

Research School of Psychology, Australian National University, Canberra, ACT, Australia

E. Kidd $(\bowtie)$

ARC Centre of Excellence for the Dynamics of Language, Australian National University, Canberra 0200, ACT, Australia

e-mail: evan.kidd@anu.edu.au

S. Nitschke

School of Psychological Sciences, The University of Manchester,

Manchester, UK research. Whereas there is strong evidence for overlap in the bilingual lexicon (e.g., Dijkstra, 2007), the degree to which bilinguals make use of common abstract grammatical representations during syntactic processing is less clear (Clahsen \& Felser, 2006; Hartsuiker \& Pickering, 2008).

Structural priming is a method particularly suited to exploring the representational nature of grammatical knowledge. Priming refers to the phenomenon whereby the processing of a primed structure eases the production or comprehension of a subsequent structure of the same type. For instance, hearing a passive prime like the car was chased by the dog increases the likelihood a speaker will subsequently use a passive form, e.g., the tree was climbed by the boy. In monolinguals priming is taken as evidence for the abstract representation of structure (Bock, 1986; Pickering \& Ferreira, 2008). In bilinguals structural priming occurs between languages (e.g., for an EnglishItalian bilingual the car was chased by the dog primes l'aboro è stato scalato dal ragazzo 'the tree was climbed by the boy'); in this population the effect is interpreted as indicative of overlapping representation of structure between languages (Hartsuiker \& Pickering, 2008; Loebell \& Bock, 2003).

One striking finding in the structural priming literature is the apparent difference between priming in production and comprehension. Production priming effects are consistently observed when there is no overlap in lexical material between prime and target, yet priming effects are higher in magnitude when a lexical head of a phrase is shared between prime and target (e.g., when prime and target share a main verb - the lexical boost). Similar effects occur in bilingual speakers, where higher production priming effects have been observed when prime and target contain translational equivalent lexical heads (Schoonbaert, Hartsuiker, \& Pickering, 2007). In contrast, the results from many studies of structural priming in comprehension suggest that priming in this modality may be dependent on the presence of lexical overlap between prime and target (see Tooley \& Traxler, 2010). This could be 
attributed to inherent differences between production and comprehension: production may rely on the precise formulation of abstract syntactic structure, whereas in comprehension structure can be recovered from lexical items like verbs, which are tagged in the lexicon with information like distributional occurrence (e.g., MacDonald, Pearlmutter, \& Seidenberg, 1994). The suggestion is that comprehension and production could be subserved by slightly different structure building mechanisms.

Several recent studies with monolingual samples suggest that this conclusion may be too strong. Firstly, although comprehension priming is less often observed in the absence of lexical overlap, abstract comprehension priming has been attested in several studies (Nitschke, Serratrice, \& Kidd, 2014; Pickering, McLean, \& Branigan, 2013; Thothathiri \& Snedeker, 2009; Traxler, 2008). Secondly, two recent studies using different methodologies have directly compared priming across modalities and (i) have observed abstract priming in comprehension in the absence of lexical overlap, and (ii) have not found differences between priming effects in comprehension versus production (fMRI data: Segaert, Kempen, Petersson, \& Hagoort, 2013; behavioural data: Tooley \& Bock, 2014). These data suggest that, at least in monolingual speakers, priming across modalities is supported by a unitary processing mechanism.

In the current study we addressed a gap in the bilingual priming literature, namely, we asked whether comprehension priming between languages is abstract, and therefore not dependent on lexico-semantic overlap between prime and target. Only two crosslinguistic comprehension priming studies have been reported in the literature, but their results are inconsistent. Weber and Indefrey $(2008,2009)$ reported two eye-tracking-while-reading studies that investigated crosslinguistic priming of the passive between English and German. An initial study reported an anti-priming effect whereby German passives were read more slowly following an English passive prime. A second study with a less complicated design reported a significant priming effect, whereby German passives primed English passives when prime and target contained translational equivalent verbs. This latter result was confirmed in a functional magnetic resonance imaging (fMRI) experiment (Weber \& Indefrey, 2009), which showed within- and cross-language language priming to be both equal in strength and supported by the same brain regions (as indexed by repetition suppression).

Therefore no studies have yet demonstrated abstract crosslinguistic comprehension priming in bilingual speakers (i.e., in the absence of lexico-semantic overlap). Just as recent studies suggest that differences in priming between production and comprehension in monolingual populations might be more apparent than real (Segaert et al., 2013; Tooley \& Bock, 2014), we suggest crosslinguistic priming in comprehension is also likely to be abstract. The current study considered this possibility by investigating priming of subject and object relative clauses (RCs) in English-German bilinguals. English subject RCs such as (1) have canonical Noun-Verb-Noun (NVN) word order, whereas English object RCs such as (2) have non-canonical NNV word order. In contrast, German subordinate clauses are verb-final; all German RCs have NNV word order [see (3)]. Therefore there is word order overlap between object RCs in English and German, but not between subject RCs.

(1) the woman that kisses the man

(2) the woman that the man kisses

(3) die Frau, die das Mädchen küsst

the woman $\left[\operatorname{subj}_{\text {/Obj] }}\right.$ that the $\operatorname{girl}_{\left[\mathrm{Subj}_{\text {/Obj] }} \text { kisses }\right.}$

Additionally, German nouns and relative pronouns are marked for gender and case. In the feminine and neuter genders the same form is used to mark nominative and accusative case, which results in a structural ambiguity when RCs contain feminine and neuter nouns. As such, (3) is structurally ambiguous; it can be parsed as either a subject or an object RC. Nitschke, Serratrice, and Kidd (2010), Nitschke et al. (2014) have shown that native speakers of German typically prefer to interpret the sentence as a subject RC, with EnglishGerman bilinguals more evenly divided between the two interpretations due to transfer from English because of word order overlap with English object RCs.

In the current study we used this ambiguity in the sentencepicture matching comprehension paradigm developed by Branigan, Pickering, and McLean (2005). In prime trials English-German bilinguals were presented with a sentence containing either an English subject or object RC and were required to match the sentence to one correct picture. In target trials they were presented with sentences containing ambiguous German RCs and their two possible interpretations. There was no lexico-semantic overlap between prime and target sentences. Priming occurred if participants persisted in their choice of interpretation across prime and target trials. Priming of ambiguous German subject and object RCs was compared to an unprimed baseline condition, and to each other. Our design therefore allowed us to test for the conditions leading to abstract crosslinguistic priming. Past crosslinguistic priming research in production has shown that priming effects are strongest when there is word order overlap between prime and target (Bernolet, Hartsuiker, \& Pickering, 2007). However, production priming is not contingent on word order overlap: studies of monolingual and bilingual speakers show that speakers also persist in their mappings of conceptual roles (e.g., agent, theme) to sentence positions and grammatical functions (Bernolet, Hartsuiker, \& Pickering, 2009; Cai, Pickering, \& Branigan, 2012). If abstract crosslinguistic comprehension priming is dependent on word order overlap between prime and target, we should only observe priming in the 
object RC condition, where there is constituent word order overlap between English object RCs and ambiguous German RCs (i.e., NNV). A significant priming effect for subject RCs would indicate abstract priming of the order of conceptual/ grammatical roles across languages (i.e., English: $\mathrm{N}_{\text {subj/agent }} \mathrm{V}$ $\mathrm{N}_{\text {object/patient }} \rightarrow$ German: $\mathrm{N}_{\text {subj/agent }} \mathrm{N}_{\text {object/patient }} \mathrm{V}$ ).

\section{Method}

\section{Participants}

Twenty-seven $(\mathrm{N}=27)$ English-German bilinguals participated (mean age $=26.27$ years, $S D=9.87$ ). All had English as their L1; the average age at which they began learning German was 13.7 years $(S D=7.5)$. Sixteen were recruited from advanced German classes in an Australian university (i.e., they were in their final year of a three-year German language major). A further 11 people were recruited through personal contacts in the German-speaking community in Canberra, Australia. These participants had either completed formal tuition in German at university, institutions such as the Volkshochschule, or through the German education system itself. One participant was excluded from the final analyses because of low accuracy on the unambiguous English prime trials $(33 \%)$. Since our participants had not all taken formal proficiency exams (e.g., Goethe-Zertifikat), we gauged their proficiency by asking their final grade in the last German subject they had taken. The modal score was a Distinction (70-79\%) or equivalent (range: $59-90 \%){ }^{1}$ On average, the participants had been speaking German for 12.5 years $(S D=$ 8.67). Twenty-five of the 26 participants had spent time in a German-speaking country ( $M=4$ years, 4 months, range: 1 month-15 years), 14 of them having spent a year or more in German-speaking parts of the world. Participants received $\$ 10$ to compensate for their time.

Materials and procedure

Fifty-six pairs of pictures depicting reversible transitive actions were used. The pictures were assembled from 16 different human animate characters and 16 different verbs (see Nitschke et al., 2014). Importantly, all characters had either feminine or neuter gender in German, where there is morphological ambiguity between nominative and accusative case, making all target German NNV RCs describing the pictures ambiguous between subject and object RC readings. Thirtytwo pictures served as targets, and 24 served as primes.

\footnotetext{
${ }^{1}$ Not all participants provided numerical scores, instead providing grade bands. Therefore we do not report means.
}

The participants were told that they were participating in a study that was investigating language comprehension in English native speakers who had advanced knowledge of German. All participants were tested in a quiet room using a DELL Latitude XT3 laptop with a 14-in screen. A sentencepicture matching task was used (Nitschke et al., 2010, 2014; Branigan et al., 2005). The experiment was presented using EPrime 2.0 (Psychology Software Tools, Pittsburgh, PA, USA; Schneider, Eschman, \& Zuccolotto, 2002). A schematic representation of a prime-target trial is presented in Fig. 1. Participants first read an English prime sentence on the computer monitor (black text, size 14 courier font, white background). Once they understood the sentence they were instructed to push a button on a button box, which revealed two pictures. The participants' task was to indicate which picture best represented the meaning of the sentence by pressing one of two buttons on the button box. Following the prime sentence the participants were presented with the target sentence, which contained an ambiguous German RC (e.g., Wo ist die Malerin, die die Hexe schlägt? $\rightarrow$ "Where is the painter [Subj/Obj] that the witch ${ }_{[\mathrm{Obj} / \mathrm{Subj}]}$ hit?). As in the prime trial, participants were required to read the target sentence and then choose the picture that best depicted their interpretation of the sentence. There was no lexico-semantic overlap between prime and target sentences; that is, there were no cognate or translational equivalent words shared between prime and target sentences. Therefore any observed priming effect suggests abstract syntactic representations shared between languages. The location of the pictures was counterbalanced across the experimental orders.

1. Where is the princess that the child is pushing?

2.
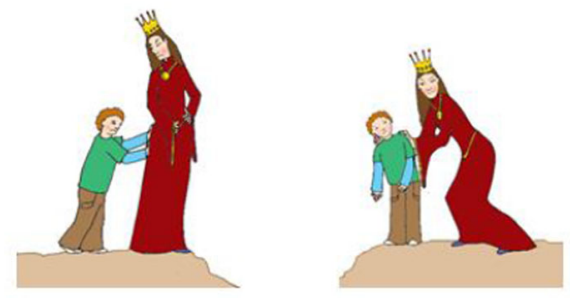

3. Wo ist die Malerin, die die Hexe schlägt?

4.
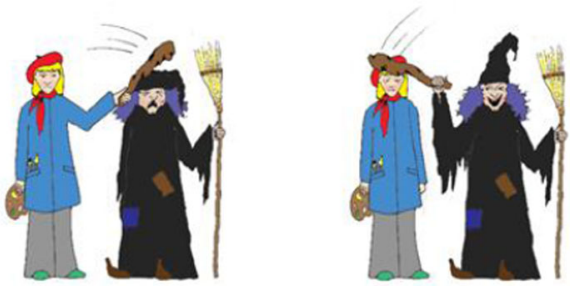

Fig. 1 Example of prime-target test item 
The priming task had three within-participants conditions: (i) baseline, (ii) subject RC primes, and (iii) object RC primes. In an initial baseline condition eight ambiguous German RC targets were preceded by an unrelated filler sentence. In the subsequent subject RC and object RC conditions target sentences were preceded by English subject RC and object $\mathrm{RC}$ primes, respectively. Twelve subject $\mathrm{RC}$ and 12 object $\mathrm{RC}$ prime-target trials were interspersed together, with the restriction that there could be no more than two same-RC prime trials in a row (separated by $2-5$ fillers). All target ambiguous German RCs were rotated as targets through the three prime conditions across eight pseudorandomized lists. There were 110 German and English filler sentences. Thirty-two of the filler sentences contained prepositional phrase-attachment ambiguity, half in English and half in German (e.g., the policeman hits the doctor with the hammer/der Polizist schlagen den Arzt mit dem Hammer). These sentences served to divert the attention of any participants who recognized the structural ambiguity in the German RCs away from the purpose of the experiment. The remaining fillers were unambiguous active (e.g., the boy is eating a banana), intransitive (e.g., the girl is laughing), and passive (e.g., the girl is followed by the boy) sentences. Participants were interviewed after the experiment in order to ascertain whether they had identified the purpose of the study; none recognized the contingency between prime-target trials.

\section{Results}

Responses to prime trials were coded as correct/incorrect; responses to target trials were coded as subject $\mathrm{RC}$ interpretation ( $=0)$ and object RC interpretation $(=1)$. Accuracy on the unambiguous English prime trials was high $(M=$ $97.1 \%)$. Only those prime-target trials in which participants correctly interpreted the prime sentence were included. Figure 2 presents the proportion of object RC responses by condition.

Figure 2 shows that the proportion of object RC interpretations in the baseline condition and following English subject RC primes was similar $\left(M_{\text {baseline }}=.54, M_{\text {SubRC }}=.56\right)$, but was higher following English object RC primes $\left(M_{\mathrm{ObjRC}}=.65\right){ }^{2}$ The data were analyzed using Generalized Linear Mixed Models (Baayen, Davidson, \& Bates, 2008; Jaeger, 2008), which were calculated using the lme 4 package for Linear

\footnotetext{
${ }^{2}$ The high number of object RC interpretations in the baseline data can be attributed to L1 transfer from English. Specifically, the overlap in word order between English object RCs and German RCs leads to a greater number of object RC interpretations in general (see Nitschke et al., 2010). This in itself is (indirect) evidence for a cross-linguistic representational link.
}

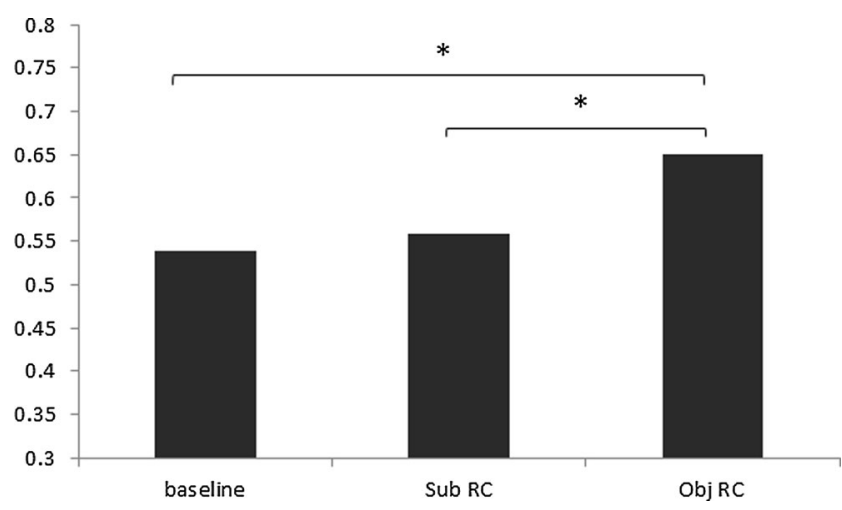

Fig. 2 Proportion of object RC target responses by condition (* denotes difference between conditions significant at $p<.05) . R C$ relative clause

Mixed Effects (Bates \& Maechler, 2010) in $R$ (version 2.15.2, R Core Development Team, 2012). We fitted a model to the data that included the independent variable of prime type (three levels: baseline, Subject RC, Object RC) and random intercepts for participants and items. A preliminary analysis that included years speaking German (zero-centred) as a covariate showed that this did not significantly add to the model. The fixed effect of prime was centred at 0 with a range of 1 to reduce the risk of collinearity. Random slope parameters for the independent variable of prime type were included in the model using forward selection: each random slope was added sequentially to the model, first for participants and then items, and the ANOVA function was used to determine whether the additional random slope significantly improved the model (Baayen, 2008). The inclusion of the main effect of prime improved model fit in comparison to a null model containing only random effects $\left(\chi^{2}(2)=11.95, p=.003\right)$. The final model had prime as a fixed effect, and participant and item intercepts and participant slope for the fixed effect of prime as random effects. The intercept was not significant $(\beta=$ $.22, \operatorname{SE}(\beta)=.28$, Wald $\mathrm{z}=.76, p=.45$ ), suggesting an even number of subject and object RC interpretations of ambiguous German RCs overall. Pairwise comparisons across prime conditions are shown in Table 1. They show that English object RCs primed significantly more German object RC interpretations in comparison to baseline and English subject RC primes, which did not differ from each other.

Table 1 Pairwise comparisons among primes

\begin{tabular}{lllll}
\hline & $\beta$ & $\operatorname{SE}(\beta)$ & Wald $z$ & $p$ \\
\hline Base vs. Subj RC & .19 & .31 & .61 & .54 \\
Base vs. Obj RC & .7 & .29 & 2.41 & $.016^{*}$ \\
Sub RC vs. Obj RC & .5 & .22 & 2.27 & $.023^{*}$ \\
\hline
\end{tabular}

$* p<.05 ; R C$ relative clause 


\section{Discussion}

The results showed that English object RCs prime object RC interpretations of ambiguous German RCs, but that English subject RCs do not prime subject RC interpretations. Priming was therefore only observed in instances of word order overlap between the two languages. This is the first demonstration of abstract structural crosslinguistic priming in comprehension. The results are consistent with recent demonstrations of abstract comprehension priming in monolingual samples (Pickering et al., 2013; Segaert et al., 2013; Tooley \& Bock, 2014). They suggest that bilingual speakers make use of common abstract grammatical representations in comprehension, as has been shown for production.

The fact that priming was only observed in instances of word order overlap warrants further attention. The result suggests that the locus of priming might be syntactic: repetition of the linear surface string of constitutents across prime and target increases the likelihood that ambiguous German RCs are parsed as object RCs. This explanation is supported by the fact that there was no priming in the subject RC condition, which would have indicated thematic role priming (or thematic emphasis, see Vernice, Pickering, \& Hartsuiker, 2012). Crosslinguistic priming has been shown to be strongest in instances of word order overlap, although as in monolingual populations priming at the level of conceptual representation has been demonstrated (Bernolet et al., 2009). Therefore we do not rule out the possibility of conceptual-level priming in comprehension, an issue to which we return below.

The data are consistent with the dominant model of bilingual syntactic representation - Hartsuiker and Pickering's (2008) lexico-syntactic model. In the model, syntactic processes are shared between languages given sufficient similarity between structures, which the bulk of research appears to suggest is surface word order overlap. For instance, Hartsuiker, Pickering, and Veltkamp (2004) reported that the Spanish passive primed the English passive, whereas the same has not been found in German-English bilinguals (Loebell \& Bock, 2003, though see Weber \& Indefrey, 2009). The difference between the two language pairs is that there is word order overlap between the English and Spanish passives, whereas this is not the case for English and German (see also Bernelot et al., 2007). Therefore, all verbs in Spanish and English that can be passivized will be linked to a shared syntactic node that specifies the syntactic operation to form a passive. The current data suggest this representational structure is used in comprehension as well as in production.

The data can also be explained by learning-based accounts. Chang, Dell, and Bock's (2006) connectionist model uses error-based learning to both learn production representations (via comprehension) and exhibit priming. The model is biased to prefer to build structural representations which encode word order information, which explains why monolingual priming is in some circumstances insensitive to changes in thematic roles (Bock \& Loebell, 1990). However, when structure is insufficient to distinguish meaning, as in the English locative alternation (both structures are NP V NP PP), the model incorporates thematic roles into its syntactic representations. On this account, English speakers should have purely structural representations for the RCs, since the subject and object RC structures are distinct in word order. This raises the possiblity that English learners of German, such as the participants in the current study, may not have fully distinct structural representation for English and German RCs because they can make use of their L1 English object RC structure to support the acquisition and processing of both German RCs, explaining the object RC priming effect. Native German speakers, on the other hand, cannot use word order to distinguish these structures, so the model predicts that their syntactic structures for RCs should incorporate thematic role information. That is, the model predicts that monolingual speakers of German should show thematic role priming in $\mathrm{RC}$ structures.

One final point to consider is the degree to which the differential structural frequency of subject and object RCs contributed to our priming effect. Consistent with the wellestablished inverse frequency effect (Pickering \& Ferreira, 2008), it is possible and indeed likely that the English object $\mathrm{RC}$ primes promoted a patient-first interpretation of the ambiguous German RC targets because they are infrequent and therefore unexpected. This does not negate the demonstration of an abstract cross-language link between the two structures that is supported by surface word order overlap and is used in comprehension. Rather, the two constraints may be additive: the relative low frequency of object RCs could serve to promote a patient-first interpretation of German ambiguous RCs, which is supported by the cross-language representational link.

To our knowledge, the current data constitute the first demonstration of positive crosslinguistic structural priming in comprehension. Thus we have observed the existence and use of shared abstract syntactic structure between languages in comprehension, which appears to be particularly dependent on word order overlap between functionally equivalent structures between languages. Therefore, as in studies of sentence production, bilingual speakers make use of abstract integrated syntactic representations during sentence comprehension.

Acknowledgments We thank Louise Jansen and Gabriele Schmidt for help with recruitment, and Franklin Chang for commenting on an earlier draft. We also thank two anonymous reviewers for helpful comments.

\section{References}

Baayen, R. H. (2008). Analyzing linguistic data. A practical introduction to statistics using R. Cambridge University Press. 
Baayen, R. H., Davidson, D. J., \& Bates, D. M. (2008). Mixed-effects modeling with crossed random effects for subjects and items. Journal of Memory and Language 59, 390-412.

Bates, D., \& Maechler, M. (2010). lme4: Linear mixed-effects models using S4 classes. R package version 0.999375-33.

Bernolet, S., Hartsuiker, R. J., \& Pickering, M. J. (2007). Shared syntactic representations in bilinguals: Evidence for the role of word-order repetition. Journal of Experimental Psychology: Learning, Memory, and Cognition, 33, 931-949.

Bernolet, S., Hartsuiker, R. J., \& Pickering, M. J. (2009). Persistence of emphasis in language production: A crosslinguistic approach. Cognition, 112, 300-317.

Bock, J. K. (1986). Syntactic persistence in language production. Cognitive Psychology, 18, 355-387.

Bock, J. K., \& Loebell, H. (1990). Framing sentences. Cognition, 35, 1-39.

Branigan, H. P., Pickering, M. J., \& McLean, J. F. (2005). Priming prepositional-phrase attachment during comprehension. Journal of Experimental Psychology: Learning, Memory, and Cognition, 31, $468-481$.

Cai, Z. G., Pickering, M. J., \& Branigan, H. P. (2012). Mapping concepts to syntax: Evidence from structural priming in Mandarin. Journal of Memory and Language, 66, 833-849.

Chang, F., Dell, G., \& Bock, K. (2006). Becoming syntactic. Psychological Review, 113, 234-272.

Clahsen, H. \& Felser C. (2006). How native-like is non-native language processing? Trends in Cognitive Sciences, 10, 564-570.

Dijkstra, A. (2007). The multilingual lexicon. In M. G. Gaskell (Ed.), Oxford handbook of psycholinguistics (pp. 251-265). Oxford: Oxford University Press.

Hartsuiker, R. J., \& Pickering, M. J. (2008). Language integration in bilingual production. Acta Psychologica, 128, 479-489.

Hartsuiker, R. J., Pickering, M. J., \& Veltkamp, E. (2004). Is syntax separate or shared between languages? Psychological Science, 15, 409-414.

Jaeger, T. F. (2008). Categorical data analysis: Away from ANOVAs (transformation or not) and towards logit mixed models. Journal of Memory and Language, 59, 434-446.

Loebell, H., \& Bock, J. K. (2003). Structural priming across languages. Linguistics, 41, 791-824.

MacDonald, M. C., Pearlmutter, N. J., \& Seidenberg, M. S. (1994). Lexical nature of syntactic ambiguity resolution. Psychological Review, 101, 676-703.

Nitschke, S., Kidd, E., \& Serratrice, L. (2010). First language transfer and long-term structural priming in comprehension. Language and Cognitive Processes, 25, 94-114.
Nitschke, S., Serratrice, L., \& Kidd, E. (2014). The effect of linguistic nativeness on structural priming in comprehension. Language, Cognition and Neuroscience, 29, 525-542.

Pickering, M. J., \& Ferreira, V. S. (2008). Structural priming: A critical review. Psychological Bulletin, 143, 427-459.

Pickering, M. J., McLean, J. F., \& Branigan, H. P. (2013). Persistent structural priming and frequency effects during comprehension. Journal of Experimental Psychology: Learning, Memory, and Cognition, 39, 890-897.

R Core Team. (2012). $R$ : A language and environment for statistical computing. Vienna, Austria: R Foundation for Statistical Computing. ISBN 3-900051-07-0, http://www.R-project.org

Schneider, W., Eschman, A., \& Zuccolotto, A. (2002). E-Prime: User's guide. Pittsburgh, PA: Psychology Software Incorporated.

Schoonbaert, S., Hartsuiker, R. J., \& Pickering, M. J. (2007). The representation of lexical and syntactic information in bilinguals: Evidence from syntactic priming. Journal of Memory and Language, 56, 153171.

Segaert, K., Kempen, G., Petersson, K. M., \& Hagoort, P. (2013). Syntactic priming and the lexical boost effect during sentence production and sentence comprehension: An fMRI study. Brain and Language, 124, 174-183.

Thothathiri, M., \& Snedeker, J. (2009). Give and take: Syntactic priming during spoken language comprehension. Cognition, $108,51-68$.

Tooley, K. M., \& Bock, K. (2014). On the parity of structural persistence in language production and comprehension. Cognition, 132, 101136.

Tooley, K. M., \& Traxler, M. J. (2010). Syntactic priming effects in comprehension: A critical review. Language and Linguistics Compass, 4, 925-937.

Traxler, M. J. (2008). Lexically-independent syntactic priming of adjunct relations in on-line sentence comprehension. Psychonomic Bulletin and Review, 15, 149-155.

Vernice, M., Pickering, M. J., \& Hartsuiker, R. J. (2012). Thematic emphasis in language production. Language and Cognitive Processes, 27, 631-664.

Weber, K., \& Indefrey, P. (2008). Syntactic priming in German-English bilinguals during sentence comprehension: RT and fMRI studies. Radboud University Nijmegen - Cognitive Neuroscience Journal, 3, $1-16$.

Weber, K., \& Indefrey, P. (2009). Syntactic priming in German-English bilinguals during sentence comprehension. NeuroImage, 46, 1164 1172 . 